American Journal of Pharmaceutical Education 2020; 84 (11) Article 7920.

\title{
BRIEF
}

\section{Pharmacy Students' Perceptions and Performance on the Use of an Online Virtual Experience Tool for Practicing Objective Structured Clinical Examinations}

\author{
Angelina S. Lim, PhD, ${ }^{\text {a }}$ Shaun Wen Huey Lee, PhD, MPharm, ${ }^{\mathrm{b}}$ Nilushi Karunaratne, $\mathrm{PhD},{ }^{\mathrm{a}}$ \\ Suzanne Caliph, $\mathrm{PhD}, \mathrm{MPharmSci}{ }^{\mathrm{a}}$ \\ ${ }^{a}$ Monash University, Faculty of Pharmacy and Pharmaceutical Sciences, Melbourne, Victoria, Australia \\ b Monash University Malaysia, School of Pharmacy, Jalan Lagoon Selatan, Bandar Sunway, Malaysia \\ Submitted November 6, 2019; accepted June 5, 2020; published November 2020.
}

Objective. To examine pharmacy students' performance on and perceptions regarding the use of an interactive online tool for practicing to take objective structured clinical examinations (OSCEs).

Methods. The Monash OSCE Virtual Experience (MOVE), an online module consisting of 20 pharmacy case scenarios with virtual patients, was piloted with final-year pharmacy students at Monash University campuses in Australia and Malaysia. A mixed methods approach that included reviewing user attempts and comparing grades, collecting student-administered questionnaires, and holding focus groups was used to examine students' perception and performance.

Results. More than $99 \%$ of all students attempted at least one online case scenario in preparation for their final in-person OSCE, and $81 \%$ attempted all 20 scenarios two or more times. Ninety percent of students at the Malaysia campus and $70 \%$ of students at the Australia campus reported that MOVE was a helpful study tool for their OSCE preparation. However, a raw comparison of user attempts and OSCE grades did not find a direct correlation between online module attempts and assessment grades. Self-administered questionnaire and focus group results indicated that MOVE prepared students for targeted and time-restricted history-taking and problem-solving skills. Overall, students perceived MOVE to be a useful learning tool and a less overwhelming learning experience than were face-toface sessions. Nevertheless, students still preferred face-to-face OSCE practice with simulated patients over online practice with virtual patients.

Conclusion. The Monash OSCE Virtual Experience was perceived by our students as a flexible and useful online learning aid in preparing for their final-year OSCE However, there was no direct correlation between online practice attempts and students' exam grades.

Keywords: pharmacy, objective structured clinical examination OSCE, virtual patients, simulation, online learning

\section{INTRODUCTION}

Objective structured clinical examinations (OSCEs) have been the gold standard for evaluating clinical skills in health care worldwide. ${ }^{1,2}$ Objective structured clinical examinations allow educators to assess students' clinical knowledge, communication, and problem-solving skills in a time sensitive, simulated environment, making the examination more rigorous than written examinations. In pharmacy education, OSCEs are an increasingly popular method to assess the knowledge and skills of pharmacy

Corresponding Author: Suzanne Caliph, Faculty of Pharmacy and Pharmaceutical Sciences, 381 Royal Parade, Parkville, Victoria 3052, Australia. Tel: +61 399039682. Email: suzanne.caliph@monash.edu students for registration, licensing, and certification. ${ }^{2-7}$ Objective structured clinical examinations can be summative or formative. Formative OSCEs can help orient students to the OSCE process and allow them to practice their skills in a low-stakes environment prior to completing a summative version of the real assessment. ${ }^{8}$

The balance between managing resourcing for OSCEs and allowing students enough opportunity for practice has been a constant struggle. Use of online learning resources has been shown to assist student learning, enhance performance, and reduce staff workload and cost. ${ }^{9,10}$ Virtual patients in online case scenarios have been used successfully in recent years in medical, ${ }^{11}$ nursing, ${ }^{12}$ occupational therapy, ${ }^{13}$ and pharmacy training to help prepare students for working with simulated patients in a real OSCE. ${ }^{7,10,14-18}$ 


\section{American Journal of Pharmaceutical Education 2020; 84 (11) Article 7920.}

In particular, OSCEs are helpful in upskilling pharmacy students in conducting clinic visits, ${ }^{19}$ history taking, developing pharmaceutical care plans, and clinical problem solving. ${ }^{20}$ Simulated patients are individuals (commonly professional actors) who are trained to portray a patient with a specific condition in a standardized, realistic way so that students can be tested in a controlled environment such as an OSCE. ${ }^{21}$ Substituting well-designed virtual patients in place of live simulated patients in order to prepare students for OSCEs has the advantage of providing students with the opportunity for access, flexibility, and repeated practice, an approach that would be costly and difficult to implement in face-to-face sessions. Repeated exposure to online case scenarios using virtual patients can increase students' confidence in their performance. ${ }^{19}$ Using virtual patients also ensures that all situations are standardized, ${ }^{22}$ giving each student the same consistent practice experience and responses, which is challenging to achieve in face-to-face practice.

At our institution, we have two pharmacy campuses, one in Melbourne, Australia, and one in Sunway, Malaysia, which deliver the same curriculum simultaneously. We use OSCEs as formative and summative measures throughout the four-year Bachelor of Pharmacy degree program on both campuses. Summative OSCEs are conducted at the end of every year and are embedded in a unit and serve as a hurdle assessment for that particular unit. A graduated approach is used in terms of how many stations the OSCE has and the overall level of difficulty of the OSCE (moving from one OSCE station on a fixed particular content area to four OSCE stations on any content area). In years 1 and 2 of the pharmacy program, formative OSCEs (practice attempts with feedback) are conducted as small-group face-to-face tutorials with a 1:4 staff member to student ratio, allowing for personalized feedback. However, this approach has proven to be very resource demanding. Because of this, the formative OSCEs conducted in years 3 and 4 are held in large classes, and only the small number of students who volunteer to participate in the role-play with the facilitator receive feedback from the lecturer and peers in the class.

With the advantages of online training and virtual patients in mind, we sought a more sustainable approach to OSCE preparation, particularly for final year (year 4) students who have already had several opportunities to participate in formative and summative OSCEs. While these students are already familiar with the structure and process of an OSCE, they may still benefit from more learning and practice opportunities involving a variety of topics covered across the four-year program. Our objective was to assess student use and acceptance of the online learning module, Monash OSCE Virtual Experience (MOVE), which includes virtual patients with scenarios similar to those used in actual OSCE scenarios as a means of providing students with a consistent and readily accessible learning tool to use in preparation for their final OSCE.

\section{METHODS}

In 2017, Monash University developed the Monash OSCE Virtual Experience (MOVE) using Articulate Storyline software (Micro Way Pty Ltd, New York, NY). The online learning module, which included virtual patients in scenarios similar to those in actual OSCE scenarios, was created to provide pharmacy students with a consistent and accessible learning tool to use in preparation for their final OSCE. The software program consisted of 20 pharmacy-based scenarios role-played by virtual patients. Each scenario involved medication-related problems involving classes of medicines featured in chapters of the Australian Medicines Handbook, 2017. ${ }^{23}$ Students navigated through MOVE cases by clicking on a standard set of history-taking questions to communicate with the virtual patient or doctor who responded to their questions via pre-recorded video clips. For each scenario, students were given a set time limit (seven minutes as in a real OSCE) to elicit patient information, identify medication-related problems, and recommend management options and counselling points by entering text in a textbox. Once the time lapsed, a checklist of model answers was automatically released for student feedback.

In this study, a mixed methods approach was used to assess student perception of MOVE and its impact on students' OSCE performance. Three types of data were collected and analyzed: number of user practice attempts compared with students' OSCE assessment grades, student responses on a paper-based user evaluation questionnaire, and content of focus group interviews $(n=20$ volunteers, 10 from the Australia campus and 10 from the Malaysia campus). Participation in the survey and focus groups was voluntary and anonymous. The survey and semi-structured focus group questions were related to students' preparation process for taking the in-person OSCE and students' perceptions of and experience with using MOVE for OSCE preparation. The interview conversations were audio-recorded and transcribed verbatim. Coding of the transcripts into themes was performed using NVivo (QSR International, Cambridge, MA). The data analysis of the interviews was broken down into rounds with the first round being to establish nodes based on questions posed to students in the focus groups. In the second round, a thematic analysis following the principles of Braun and Clarke ${ }^{24}$ was used to identify themes that 
American Journal of Pharmaceutical Education 2020; 84 (11) Article 7920.
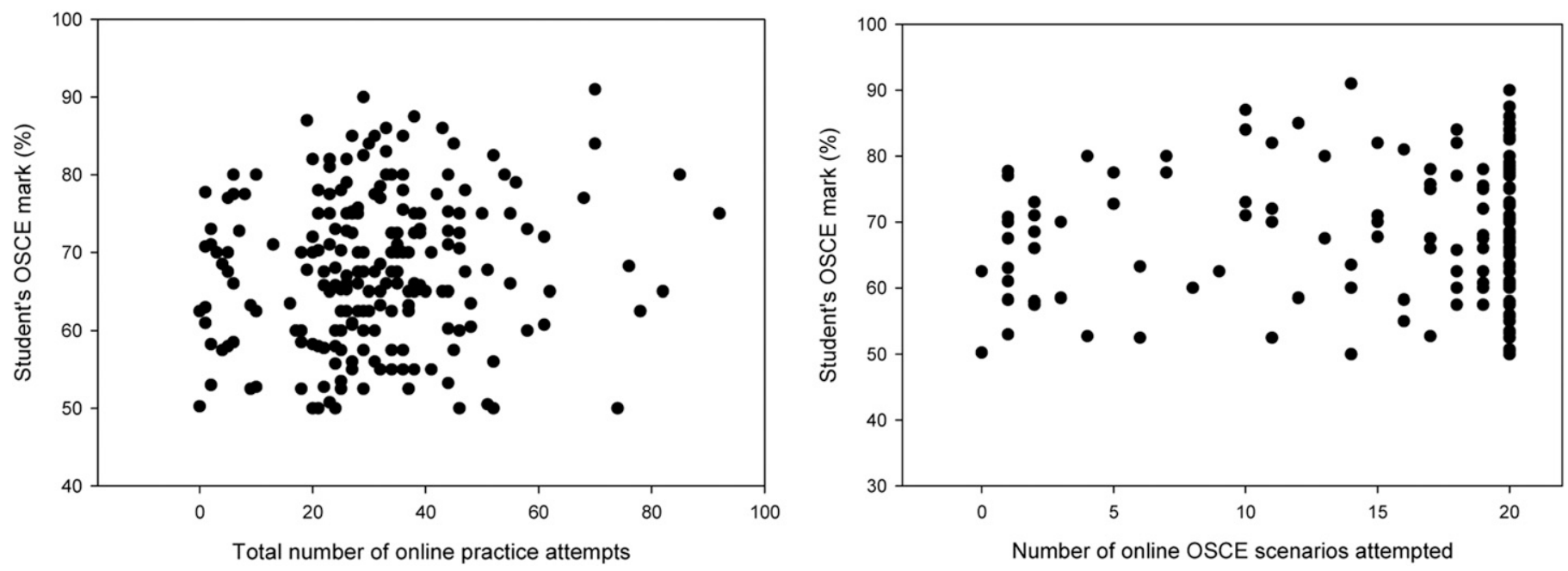

Figure 1a and 1b. Figure 1a. Comparison of total number of online practice attempts vs. students' grades in OSCE Figure 1b. Comparison of number of online OSCE scenarios attempted vs. students' grades in OSCE

emerged with each node. Finally, a peer review process was conducted by an independent reviewer to add rigor to the data analysis process. ${ }^{25}$ This project was approved by the Monash University Human Research and Ethics Committee.

\section{RESULTS}

More than $99 \%$ of all students (193/195 [99\%] in Australia and 40/40 [100\%] in Malaysia) completed at least one of the online case scenarios, and $81 \%$ of students attempted all 20 scenarios. More than 7000 attempts were documented across both campuses with usage data increasing substantially during the last two weeks preceding the in-person OSCE. Raw comparison of individual user attempts and final OSCE grades of the whole cohort showed there was no direct correlation between students' online practice attempts and final assessment performance (Figure 1a and 1b).

One hundred twenty students (response rate $=50.8 \%$ ) completed the student perception questionnaire. Students' perceptions about the usefulness of MOVE for OSCE preparation are presented in Table 1. The MOVE was ranked the most-used method of OSCE preparation by students on the Australia campus and the second most-used method of preparation by students on the Malaysia campus. Approximately $90 \%$ of students in Malaysia and $70 \%$ of students in Australia reported MOVE to be helpful for their OSCE preparation. Those who did not access MOVE cited lack of time and being unsure about how an online module could help with OSCE preparation as the main reasons for not using the software. The OSCE topic that students felt most prepared to manage correlated well with Moodle analytics of student attempts of the topic in the final two weeks before the examination.
Ten students on each campus were recruited by convenience sampling to participate in a focus group. Six themes emerged from the two focus groups. Key quotes and findings are presented in Appendix 1.

\section{DISCUSSION}

The design and delivery of MOVE was well received by Monash University pharmacy students on both campuses, and the majority of students found it useful for OSCE preparation. Having a standard set of history taking questions and a set time limit in which to interact with virtual patients to identify and manage their medicationrelated problems, students learnt the importance of patient-centered questioning technique and time management using this online learning tool. Students also found the MOVE feedback tool useful for reflection and identifying gaps in their clinical and product knowledge that they needed to address prior to completing the real OSCE. Allowance for repeated practice with virtual patients increased students' confidence in tackling complex case problems, which is consistent with other studies where pharmacists showed they were more likely to use a medication therapy management program after completing virtual cases. ${ }^{10}$

In this study, students indicated that a virtual simulation tool such as MOVE could serve as an additional resource to prepare them for engaging in face-to-face OSCE practice sessions, which they preferred. Similar to our findings, Al-Dahir and colleagues ${ }^{18}$ reported that pharmacy students in their study rated the traditional faceto-face facilitator-led environment favorably compared to a self-directed virtual learning environment. The limitations that the students identified about MOVE included the software program's inability to give them personalized 


\section{American Journal of Pharmaceutical Education 2020; 84 (11) Article 7920.}

Table 1. Pharmacy Students' Responses to a Self-administered Questionnaire Assessing Their Perceptions of the Monash OSCE Virtual Experience to Prepare Them for Objective Structured Clinical Examinations

\begin{tabular}{|c|c|c|}
\hline & Students on Malaysia Campus, \% & Students on Australia Campus, \% \\
\hline \multicolumn{3}{|l|}{ "I felt prepared for OSCE" } \\
\hline Strongly Disagree & $0(0.0)$ & $4(4.8)$ \\
\hline Neutral & $20(55.6)$ & $31(36.9)$ \\
\hline Agree & $10(27.8)$ & $22(26.2)$ \\
\hline Strongly Agree & $1(2.8)$ & $2(2.4)$ \\
\hline MOVE & $30(76.9)$ & $67(73.6)$ \\
\hline Revised lecture notes & $27(69.2)$ & $39(42.9)$ \\
\hline Practiced with friends & $35(89.7)$ & $49(53.8)$ \\
\hline Spoke to previous final year students & $10(25.6)$ & $32(35.2)$ \\
\hline Very Helpful & $13 / 28(46.4)$ & $22 / 73(30.1)$ \\
\hline Somewhat Helpful & $13 / 28(46.4)$ & $28 / 73(38.3)$ \\
\hline Slightly Helpful & $2 / 28(7.1)$ & $19 / 73(26.0)$ \\
\hline Made no difference to my learning & $0(0.0)$ & $4 / 73(5.5)$ \\
\hline
\end{tabular}

Abbreviations: OSCE = objective structured clinical examination, MOVE=Monash OSCE Virtual Experience

feedback on their oral and non-oral communication skills (eg, empathy), and the lack of interaction with a real-life person in completing the OSCE.

Another limitation of MOVE was the bulk release (ie, making all of the case scenarios available to students at the same time), which may have influenced the limited number of cases that students accessed prior to the examination. Maier and colleagues found that releasing cases periodically through the year led to more balanced use compared to releasing all of the cases at the same time. ${ }^{26}$ Recommendations to other institutions who plan to use an online learning tool like MOVE for OSCE preparation would be to release small blocks of exercises over several weeks after relevant content has been taught to allow students more time to access them.

Students in our study also felt that the short amount of time allocated for online scenarios and face-to-face sessions ${ }^{27}$ could not effectively assess their abilities and skills. ${ }^{28}$ Another limitation of using virtual patients is the potential for less empathetic learners. ${ }^{29}$ The majority of respondents in our study were female, which was consistent with enrollment statistics for gender. In another study, female students found training using virtual patients to be more beneficial than did male students. ${ }^{30}$ Although the two campuses, one in Malaysia and the other in Australia, are culturally different, we did not find students' perceptions of MOVE to differ significantly.
Raw comparison of students' online practice attempts with OSCE assessment scores for the whole cohort demonstrated no significant correlation, indicating virtual learning engagement alone could not sufficiently impact students' OSCE performance in real life. In this regard, the user survey results and focus group interview results showed that students used a variety of OSCE preparation methods in addition to completing the online modules in MOVE, including recruiting peers to role play MOVE cases in person. Nevertheless, students from both the Australia campus and the Malaysia campus felt that online practice attempts helped them prepare for the OSCE, in particular, their history-taking, problem-solving, and time management skills. Similar to our finding, Tarileri and colleagues ${ }^{19}$ reported that pharmacy students access to virtual patient activities prior to mock clinical visits improved student performance in real life. Practice with virtual patients provided additional learning opportunities and positive outcomes for pharmacy students.

While virtual patients and online simulation cannot completely duplicate the experience of real-life human interactions, MOVE provided a controllable, secure, and safe learning environment with an opportunity for unlimited access and learning attempts without the restrictions on time and space normally incurred with face-to-face practice sessions. ${ }^{22}$ Lack of easy access to technology has been suggested as one of the barriers to student use of virtual 


\section{American Journal of Pharmaceutical Education 2020; 84 (11) Article 7920.}

patient technology as well as the ability to engage with online learning materials which may also be challenging for some students. ${ }^{6}$

Finally, we listed the online cases in alphabetical order and we found that the most accessed cases were the ones starting with "a" such as "allergy" and some of the last cases were missed (data not shown). We suggest that educators use a portal that randomly allocates a case (eg, hospital, community, prescription, drug chart, product request) to the student for each practice session. Then, once the student has attempted all cases, they will have the ability to repeat any case. It may be beneficial to go over several example cases with students in a face-to-face session to enhance student engagement, learning experience, and outcomes.

In summary, the use of virtual patients and simulated scenarios can be a feasible and effective way of providing student-centered learning. ${ }^{31}$ However, it is still a supplementary tool and does not replace the spontaneity of human interaction achieved when live simulated patients are used. Future directions include looking into incorporating verbal and non-verbal communication practice.

\section{CONCLUSION}

The Monash OSCE Virtual Experience was well received by pharmacy students on two campuses as an online learning tool to aid them in preparation for OSCEs. This online learning tool, which uses simulated patients and physicians, is intended to supplement rather than replace the real human interaction that takes place in an actual OSCE. Additional work is required to integrate verbal and non-verbal communication practice more comparable to authentic face-to-face live practice.

\section{ACKNOWLEDGMENTS}

The authors would like to thank Keith Sewell, Kaan Gangur, and Ching Koo for their technical assistance in the development of MOVE. The authors would like to also thank Drs. Tina Brock, Kayley Lyons, Vivienne Mak, and Paul White for their review of the manuscript drafts.

\section{REFERENCES}

1. Harden RM, Gleeson FA. Assessment of clinical competence using an objective structured clinical examination (OSCE). Med Educ. 1979;13(1):41-54.

2. Shirwaikar A. Objective structured clinical examination (OSCE) in pharmacy education - a trend. Pharm Pract. 2015;13(4):627.

3. Austin Z, O'Byrne C, Pugsley J, Munoz LQ. Development and validation processes for an objective structured clinical examination (OSCE) for entry-to-practice certification in pharmacy: the Canadian experience. Am J Pharm Educ. 2003;67(3):Article 76.
4. Awaisu A, Nik Mohamed MH, Mohammad Al-Efan QA. Perception of pharmacy students in Malaysia on the use of objective structured clinical examinations to evaluate competence. Am J Pharm Educ. 2007;71(6): Article 118.

5. Rutter P. The introduction of observed structured clinical examinations (OSCEs) to the M.Pharm degree pathway. Pharm Educ. 2001;1(3):173-180.

6. Corbo M, Patel J, Abdel Tawab R, Davies J. Evaluating clinical skills of undergraduate pharmacy students using objective structured clinical examinations (OSCEs). Pharm Educ. 2006;6(1): 53-58.

7. Brock TP, Deloatch KH, McDermott JH, et al. Objective structured clinical examinations as an assessment tool in pharmacy curricula. J Pharm Teach. 2002;9(2):1-16.

8. Barnes K, Graham M. Impact of teaching OSCE implementation on student performance in a pharmacotherapy course: 79 .

Pharmacotherapy. 2016;36(12):e223.

9. Zlotos L, Thompson ID, Boyter AC. Integration of an online simulated prescription analysis into undergraduate pharmacy teaching using supplemental and replacement models. Am J Pharm Educ. 2015;79(3):Article 37.

10. Battaglia JN, Kieser MA, Bruskiewitz RH, Pitterle ME, Thorpe JM. An online virtual-patient program to teach pharmacists and pharmacy students how to provide diabetes-specific medication therapy management. Am J Pharm Educ. 2012;76(7):Article 131. 11. Oliven A, Nave R, Gilad D, Barch A. Implementation of a webbased interactive virtual patient case simulation as a training and assessment tool for medical students. Stud Health Technol Inform. 2011;169:233-237.

12. Hurst HM, Marks-Maran D. Using a virtual patient activity to teach nurse prescribing. Nurse Educ Pract. 2011;11(3):192-198.

13. Radon K, Carvalho D, Calvo MJ, et al. Implementation of virtual patients in the training for occupational health in Latin America. Int $J$ Occup Environ Health. 2011;17(1):63-70.

14. Cavaco AM, Madeira F. European pharmacy students' experience with virtual patient technology. Am J Pharm Educ. 2012; 76(6):Article 106.

15. Orr KK. Integrating virtual patients into a self-care course. $A m J$ Pharm Educ 2007;71(2):30.

16. Benedict N. Virtual patients and problem-based learning in advanced therapeutics. Am J Pharm Educ. 2010;74(8):Article 143.

17. Martini N, Datt A, Bhargava A, Webster C. Ready to practice? learning skills using digital simulated patients. E-Learn: World Conference on E-Learning in Corporate, Government, Healthcare, and Higher Education 2015. Kona, HI: Association for the Advancement of Computing in Education (AACE); 2015:15271532 .

18. Al-Dahir S, Bryant K, Kennedy KB, Robinson DS. Online virtual-patient cases versus traditional problem-based learning in advanced pharmacy practice experiences. Am J Pharm Educ. 2014; 78(4):Article 76.

19. Taglieri CA, Crosby SJ, Zimmerman K, Schneider T, Patel DK. Evaluation of the use of a virtual patient on student competence and confidence in performing simulated clinic visits. Am J Pharm Educ. 2017;81(5): Article 87.

20. Jabbur-Lopes MO, Mesquita AR, Silva LMA, De Almeida Neto A, Lyra Jr DP Virtual patients in pharmacy education. Am J Pharm Educ. 2012;76(5):Article 92.

21. Cleland JA, Abe K, Rethans JJ. The use of simulated patients in medical education: AMEE Guide No 42. Med Teach. 2009;31(6): 477-486. 


\section{American Journal of Pharmaceutical Education 2020; 84 (11) Article 7920.}

22. Deladisma AM, Cohen M, Stevens A, et al. Do medical students respond empathetically to a virtual patient? Am J Surg. 2007;193(6): 756-760.

23. Australian Medicines Handbook Pty Ltd. Australian Medicines Handbook 2017 Edition. Australia 2017.

24. Braun V, Clarke V. Using thematic analysis in psychology. Qual Res Psychol. 2006;3(2):77-101.

25. Johnson JL, Adkins D, Chauvin S. A review of the quality indicators of rigor in qualitative research. Am J Pharm Educ. 2020; 84(1):Article 7120.

26. Maier EM, Hege I, Muntau AC, Huber J, Fischer MR. What are effects of a spaced activation of virtual patients in a pediatric course? BMC Medical Education. 2013;13:45.
27. Kirton SB, Kravitz L. Objective structured clinical examinations (OSCEs) compared with traditional assessment methods. Am J Pharm Educ. 2011;75(6):Article 111.

28. Ho C-R, Lin C-M, Chung U-L. A short commentary about benefits and drawbacks of OSCEs in the nursing education. $J$ Nurs Care. 2015;5:315.

29. Kenny NP, Beagan BL. The patient as text: a challenge for problem-based learning. Med Educ. 2004;38(10):1071-1079. 30. Poulton T, Balasubramaniam C. Virtual patients: a year of change. Med Teach. 2011;33(11):933-937.

31. Edelbring S, Dastmalchi M, Hult H, Lundberg IE, Dahlgren LO. Experiencing virtual patients in clinical learning: a phenomenological study. Adv Health Sci Educ Theory Pract. 2011;16(3):331-345. 


\section{American Journal of Pharmaceutical Education 2020; 84 (11) Article 7920.}

Appendix 1. Combined Results of Focus Groups Held With Pharmacy Students on Two Campuses Regarding Their Perceptions of a Virtual Experience to Prepare Them for Objective Structured Clinical Examinations

\begin{tabular}{|c|c|c|}
\hline Theme & Key Results & Exemplar Quotes \\
\hline $\begin{array}{l}\text { 1. MOVE compliments } \\
\text { the general OSCE } \\
\text { preparation process }\end{array}$ & $\begin{array}{l}\text { Students value MOVE as an OSCE practice } \\
\text { tool but felt could not rely on it solely for } \\
\text { the exam preparation. Students indicated } \\
\text { they recruited MOVE scenarios for face to } \\
\text { face practice with peers. }\end{array}$ & $\begin{array}{l}\text { "I used MOVE, I went through each one and I } \\
\text { tested the answers on a Word document, just } \\
\text { to see what the right responses were, like } \\
\text { what you actually wanted to hear, then I } \\
\text { practiced with my friends." Parkville } \\
\text { Campus, Australia, student } \\
\text { "for the hospital cases, I think it prepares us } \\
\text { to familiarize ourselves with the resources we } \\
\text { would have to reply on..." Parkville } \\
\text { Campus, Australia, student } \\
\text { "(recommending study techniques for the } \\
\text { OSCEs) Use the MOVE module, practice } \\
\text { with your friends, if you don't have a job } \\
\text { already, get one as soon as possible, and then } \\
\text { obviously you should revise all your } \\
\text { integrated stuff, like revise on everything, but } \\
\text { that's not really realistic, especially when } \\
\text { we're trying to learn new things to pass this } \\
\text { semester. That's why you need to keep up to } \\
\text { date with the study across the } 4 \text { years." } \\
\text { Parkville Campus, Australia, student } \\
\text { "we actually found it very useful, and split } \\
\text { them to ten questions each and familiarized } \\
\text { ourselves with those MOVE cases before we } \\
\text { practiced with other people... so you can then } \\
\text { provide more solid feedback to your friends" } \\
\text { Sunway, Malaysia, student }\end{array}$ \\
\hline $\begin{array}{l}\text { 2. MOVE prepares } \\
\text { students for the } \\
\text { real OSCE }\end{array}$ & $\begin{array}{l}\text { Students questioned whether virtual patients } \\
\text { authentically prepared them for the real } \\
\text { OSCE with simulated patients. MOVE, } \\
\text { unlike in a face-to-face session, used } \\
\text { standardized answers provided by a virtual } \\
\text { patient in a video clip which students felt } \\
\text { was not mimicking a real-life exam } \\
\text { situation. Nevertheless, students also } \\
\text { indicated a practice opportunity with a } \\
\text { virtual patient was a less daunting } \\
\text { situation compared with the challenge of } \\
\text { face-to-face interaction with a simulated } \\
\text { patient. On the other hand, some students } \\
\text { found virtual interaction challenging as } \\
\text { they couldn't express their non-verbal and } \\
\text { empathy skills. }\end{array}$ & $\begin{array}{l}\text { "It's less daunting looking at someone on the } \\
\text { screen, knowing that they can't see you as } \\
\text { well. And like it's not scary at all, but if that } \\
\text { same person was right next to me and I know } \\
\text { they're marking me, I think just for myself } \\
\text { I'd get scared." Parkville student "it doesn't } \\
\text { help much with communication, just } \\
\text { questioning...right management. . and time } \\
\text { management, it's really important to have } \\
\text { friends to practice with... because everyone } \\
\text { speaks to the patient differently" Parkville } \\
\text { student “"after going through MOVE, we } \\
\text { will also practice on each other with the } \\
\text { same cases" Sunway student }\end{array}$ \\
\hline
\end{tabular}


American Journal of Pharmaceutical Education 2020; 84 (11) Article 7920.

(Continued)

\begin{tabular}{|c|c|c|}
\hline Theme & Key Results & Exemplar Quotes \\
\hline $\begin{array}{l}\text { 3. Other methods for } \\
\text { OSCE preparation }\end{array}$ & $\begin{array}{l}\text { Students reported other OSCE preparation } \\
\text { strategies such as revising lecture notes, } \\
\text { familiarizing themselves with reference } \\
\text { books and practicing with friends, which } \\
\text { aligned with the responses from the } \\
\text { questionnaires. Students also stated that } \\
\text { working part-time in a pharmacy as a } \\
\text { significant advantage over other } \\
\text { preparation methods for the OSCE. }\end{array}$ & $\begin{array}{l}\text { "Familiarize yourself with the AMH (Australian } \\
\text { Medicines Handbook). . .I usually just look } \\
\text { up drugs but in front of each drug there's a } \\
\text { section and it tells you how the treatments } \\
\text { work, the sorts of things you learn at } \\
\text { university, it's all condensed there. .I didn't } \\
\text { know it existed in the AMH." Parkville } \\
\text { student "it makes a very big difference if } \\
\text { you're working in the community } \\
\text { pharmacy...you get to see more when } \\
\text { you're working rather than just practising } \\
\text { with friends" Parkville student "if you're } \\
\text { not working in a community pharmacy, } \\
\text { it's really hard to even practice with your } \\
\text { own friends" Parkville student }\end{array}$ \\
\hline $\begin{array}{l}\text { 5. Difficulty level } \\
\text { of MOVE }\end{array}$ & $\begin{array}{l}\text { Students felt MOVE had a higher difficulty } \\
\text { level for the hospital pharmacy-based } \\
\text { scenarios than the community pharmacy } \\
\text { scenarios. Students indicated that this } \\
\text { could be because most had limited } \\
\text { exposure and work experience in } \\
\text { hospitals. }\end{array}$ & $\begin{array}{l}\text { "MOVE cases were harder than the actual } \\
\text { OSCE" Parkville student "... . after } \\
\text { completing the MOVE cases, I felt quite well } \\
\text { prepared for community cases" Parkville } \\
\text { student "the hospital cases were a lot } \\
\text { harder..." Sunway student }\end{array}$ \\
\hline
\end{tabular}

(Continued) 
American Journal of Pharmaceutical Education 2020; 84 (11) Article 7920.

(Continued)

\begin{tabular}{|c|c|c|}
\hline Theme & Key Results & Exemplar Quotes \\
\hline $\begin{array}{l}\text { 6. The comparison } \\
\text { between MOVE } \\
\text { and a face to face } \\
\text { practice session }\end{array}$ & $\begin{array}{l}\text { Students still preferred live face-to-face } \\
\text { practice as they could get individualized } \\
\text { feedback from the facilitator acting as the } \\
\text { simulated patient compared with the } \\
\text { generic feedback of item checklist } \\
\text { received from the online module. }\end{array}$ & $\begin{array}{l}\text { "MOVE responses is in a perfect world...it's } \\
\text { not reflective of what would happen really in } \\
\text { real life." Parkville student } \\
\text { "you can also like not do it properly } \\
\text { because. . I would waste like } 6 \text { minutes } \\
\text { looking at stuff, and then the last one minute } \\
\text { you can just write whatever and then click } \\
\text { submit and then all the answers will come up" } \\
\text { Parkville student "by the time you finish } \\
\text { asking all the questions and checking } \\
\text { everything, all your time's up already, and } \\
\text { then you have type out everything you want } \\
\text { to say as well, that takes even longer" } \\
\text { Parkville student "Like questions you want to } \\
\text { ask you can't ask" Parkville Student "the } \\
\text { MOVE module is difficult because there is a } \\
\text { time limit, so even when you have not } \\
\text { finished asking all the questions the time is } \\
\text { up. It's difficult. . but it was good practice to } \\
\text { ask just the specific questions." Sunway } \\
\text { student }\end{array}$ \\
\hline
\end{tabular}

Abbreviations: OSCE= Objective Structured Clinical Examination, MOVE=Monash OSCE Virtual Experience 